\title{
EL ARTE RUPESTRE POSTPALEOLÍTICO DEL CONJUNTO DE DOMINGO GARCÍA (SEGOVIA)
}

\section{The post-palaeolithic rock art of Domingo García (Segovia)}

\author{
Hipólito Pecci Tenrero ${ }^{1}$ \\ Sergio Ripoll López ${ }^{2}$
}

Recibido el 17 de mayo de 2012. Aceptado el 5 de septiembre de 2012

Resumen. En la localidad de Domingo García, Segovia, se presentaba hace más de cuatro décadas un conjunto de grabados rupestres al aire libre, los cuales abarcan diferentes ciclos crono-culturales: un claro periodo paleolítico y un gran número de representaciones postpaleolíticas sin afiliación y datación clara, que han sido objeto de estudio con el objetivo de conocer su posible ubicación cronológica, y por ende, su posible autoría.

Palabras clave: grabados, técnicas, cronología, postpaleolítico.

Abstract. In the town of Domingo García, Segovia, appeared more than four decades ago a group of open air rock engarvings, which cover different chrono-cultural cycles: a clear Palaeolithic period and a large number of representations post-palaeolithic dating unaffiliated and clear, that have been studied in order to know their possible chronological, and thus their possible authorship.

Key words: engravings, techniques, chronology, post-palaeolithic.

\section{INTRODUCCIÓN}

Con el descubrimiento del arte paleolítico se dio un paso esencial en el conocimiento de las culturas prehistóricas, de tal forma que, en los decenios finales del siglo XIX y principios del siguiente, comenzarían a surgir disertaciones acerca de la capacidad creadora en los albores de la "civilización".

Si bien, con los paulatinos descubrimientos que se iban realizando, terminó por aceptarse totalmente el hecho de que estos individuos primitivos se encontraban plenamente capacitados para llevar a cabo diferentes tipos de representaciones artísticas.

Tras una serie de avances y retrocesos, así como diferentes episodios que cuestionaban la veracidad de estas manifestaciones, ya que se llegaron a poner en duda y a cuestionar los recursos plásticos existentes en estas épocas, puesto que muchos investigadores suponían u opinaban que el Homo sapiens sapiens era incapaz de poseer ideas tan complejas que pudieran verse plasmadas en una serie de figuras concretas, se aceptaba el hecho de que el arte es inherente a la especie humana.

El devenir histórico empezaba a proporcionar un lugar destacado a las expresiones pictóricas fruto de la imaginación, la interpretación y la observación de estas primigenias poblaciones.

Los estudios e investigaciones comenzaron a difundirse con gran brío, pues en el interior del arte prehistórico, en su esencia, se vislumbraba, se percibía alguna suerte de lenguaje, un medio de comunicación impregnado de una gran carga religiosa, que en multitud de momentos poseería una intensa fuerza simbólica, pero también se convertía en un gran hilo conductor para penetrar en las formas de vida de

(1) Arqueólogo. Doctorando del Laboratorio de Estudios Paleolíticos (LEP) del Departamento de Prehistoria y Arqueología de la Universidad Nacional de Educación a Distancia (UNED).

(2) Profesor Titular de Prehistoria. Universidad Nacional de Educación a Distancia (UNED).

Departamento de Prehistoria y Arqueología. Facultad de Geografía e Historia. Universidad Nacional de Educación a Distancia (UNED). C/ Senda del Rey, 7. 28040-MADRID. 
estos primitivos grupos, al recoger y reproducir diferentes episodios de la realidad física y humana que se viviría en ese estadio concreto de la evolución.

Con el fin de la glaciación Würm, al Arte Paleolítico le sucederían otro tipo de expresiones y representaciones pictóricas, nuevos horizontes artísticos que en la Península Ibérica se han recogido genéricamente dentro del término "Arte Postpaleolítico".

En el interior de este conjunto artístico se aglutinan diversos tipos de representaciones, "Arte Levantino", expresión establecida por Juan Cabré en 1903 (Ripoll 2001), "Arte Esquemático", cuya presentación en público la llevó a cabo en el año 1868 Manuel de Góngora Martínez (Sastre 2006), el "Fenómeno Megalítico", etc., estilos cuya cronología englobaba desde momentos epipaleolíticos hasta llegar, en algún caso, al I milenio a. C.

Estas agrupaciones comprenderían diferentes zonas peninsulares, el litoral mediterráneo en el caso del Arte Levantino (Ripoll 1990), y la casi totalidad de la Península para el Arte Esquemático; no obstante, no se hallarian exentas de problemas, ya que diferentes investigadores han querido ver una continuación o evolución del primero en las representaciones esquemáticas. No obstante, esta situación, de haberse producido, únicamente sería aplicable a la zona oriental peninsular, ya que el resto del territorio no habría contado con su presencia, por lo que este tipo de manifestaciones esquemáticas deberían, en cualquier caso, haber surgido de nueva planta (Beltrán 1983).

Junto a estas expresiones parietales, dentro de la plástica postpaleolítica se incorporó un estilo, cuya zona geo- gráfica más característica y de mayor conocimiento se sitúa en la Comunidad Autónoma de Galicia, si bien, su presencia se da en otros puntos del territorio peninsular, y no es otro que el arte de los grabados, técnica utilizada, ya desde el $\mathrm{Pa}-$ leolítico Superior, y cuya presencia se observa en momentos cronológicos muy avanzados.

De esta forma el denominado Arte Postpaleolítico se nutría de diferentes expresiones y representaciones, perviviendo durante un dilatado período cronológico en el que se originaron transformaciones y se produjeron innovaciones, pero también se prolongó el uso de representaciones y técnicas de forma inalterable durante varios milenios.

En palabras de Eduardo Ripoll Perelló "...el arte postpaleolítico de la Península Ibérica tuvo una larga perduración en el tiempo en lo que podríamos llamar "zonas residuales", con el momentáneo resurgir de formas anteriores, y que pudo enlazar con ciertas manifestaciones, votivas o no votivas, altomedievales..."

Una de estas zonas se ha convertido en el objeto de nuestro trabajo, el cual conformará el Corpus de nuestra Tesis Doctoral; se trata de los grabados rupestres al aire libre ubicados en el Cerro de San Isidro, colindante con la localidad de Domingo García (Segovia).

\section{LOCALIZACIÓN}

A cuarenta kilómetros aproximadamente al Noroeste de Segovia, y a trece kilómetros de distancia siguiendo la carre-

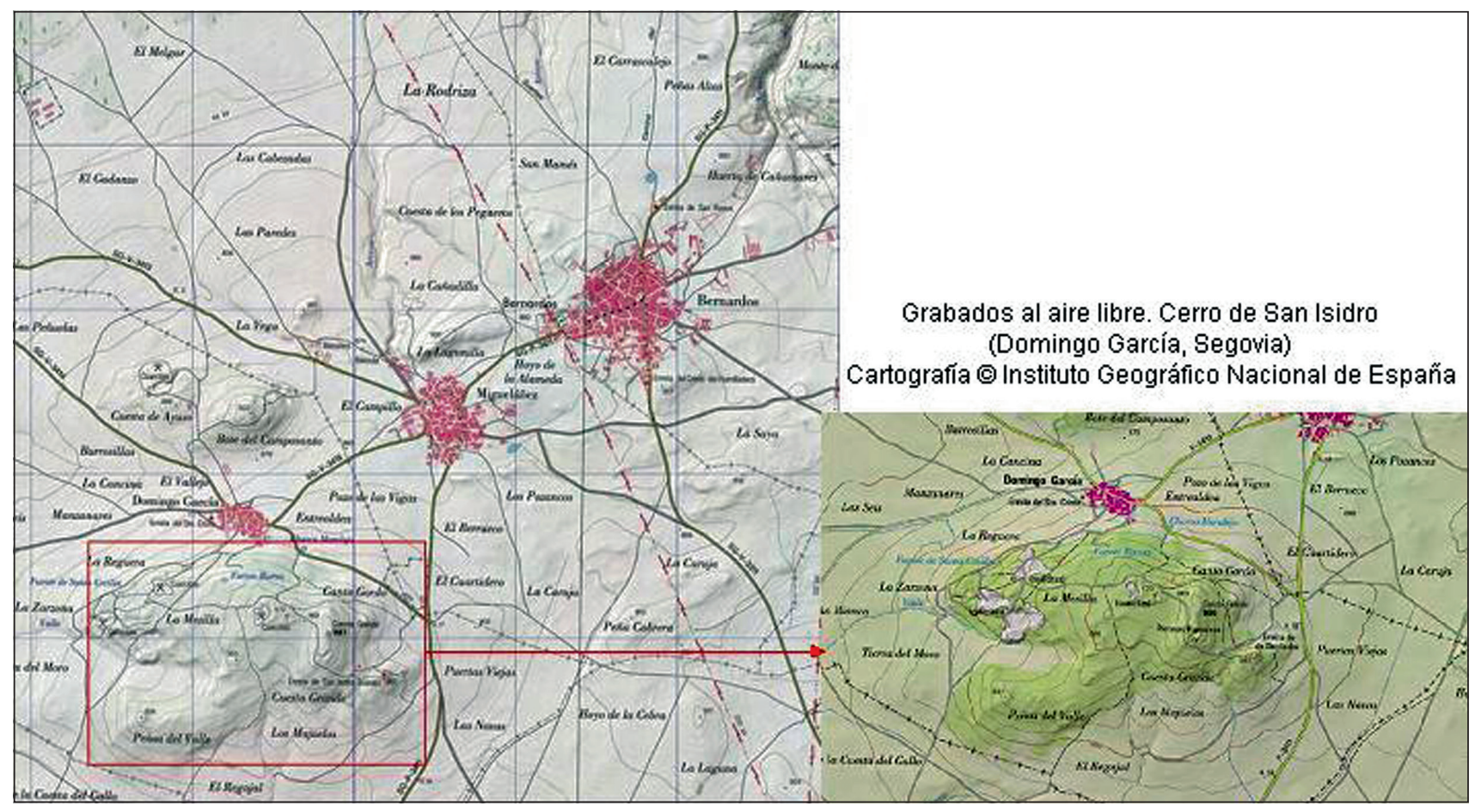

$\Delta$ Figura 1. Plano de situación de los grabados rupestres al aire libre del Cerro de San Isidro. Domingo García (Segovia). Cartografía ${ }^{\circ}$ Instituto Geográfico Nacional de España. 


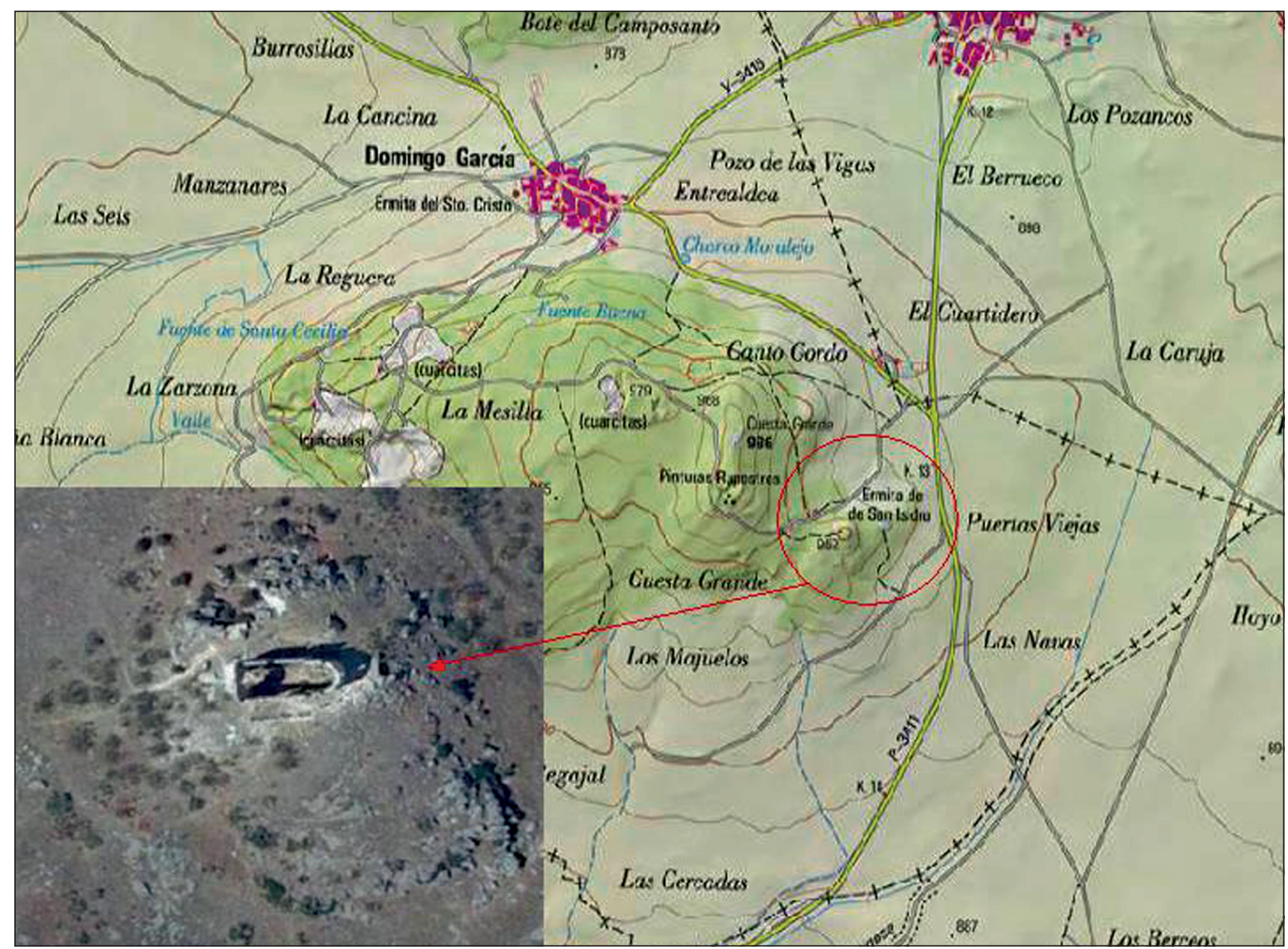

\ Figura 2. Vista aérea de la ermita de San Isidro. Domingo García (Segovia). Orientación Oste/Este. Cartografía ${ }^{\oplus}$ Instituto Geográfico Nacional de España.

tera que une las poblaciones de Carbonero el Mayor y Santa María la Real de Nieva, se ubica Domingo García, localidad ocupada por treinta y seis habitantes, según el censo del Instituto Nacional de Estadística del año 2011.

Este pequeño lugar tiene una particularidad que lo hace bastante llamativo, ya que en dirección Sur/Sureste del municipio, con unas coordenadas de $45^{\circ} 51^{\prime} 50^{\prime \prime}$ y $3^{\circ} 85^{\prime} 0^{\prime \prime}$, emerge un otero del terreno conocido como Cerro de San Isidro o Cuesta Grande, altozano que predomina sobre la planicie circundante (Fig. 1).

A simple vista esta elevación del terreno no tendría nada significativo, sin embargo, al girar la vista hacia su cima se divisan en el horizonte las formas de una antigua ermita, consagrada, según los textos, a la advocación de San Isidro, templo que permaneció en uso hasta el comienzo de la Guerra de la Independencia.

La ermita presenta un estado actual de ruina casi completa, ya que carece de cubierta, no tiene ninguna protección en sus zonas de acceso, y la mayoría de los recubrimientos de los paramentos ha desaparecido, si bien, se aprecia que su composición está formada por piedras situadas de forma horizontal y revestidas de cal.
Se encuentra formada por una única nave de planta rectangular y ábside curvo (Fig. 2), siendo la superficie total de 0,0193 hectáreas. Aledaña a esta estancia, se anexa un porche en su lado sur, en donde aparecen algunas tumbas antropomorfas, datadas en torno a los siglos IX y XI, enterramientos que también se presentan en la zona exterior del edificio, mostrando en la mayoría de los casos una orientación Oeste/Este, es decir, la cabeza al Oeste y los pies al Este, siendo ésta la disposición normal en las ceremonias de inhumación cristianas.

A la altura del año 1247 se recogen informaciones que atestiguan la existencia de la edificación, por lo que su construcción, obviamente, debió de producirse siglos antes, si bien, como un espacio de una sola pieza, testimonio que puede apoyarse también en la estructura y disposición de la ermita, ya que se advierte a simple vista, muy claramente, como el ábside en un principio no se habría erigido, tratándose de un añadido posterior.

De este modo, hay quién afirma que quizás existiera, en origen, un recinto tardorromano, argumento reforzado por el descubrimiento de un fragmento de material, previsiblemente proveniente de un capitel o un columna decorada, 
e incluso un espacio musulmán, siendo posteriormente sacralizado como recinto cristiano. No obstante, a la altura del siglo XIX el Diccionario de Pascual Madoz (1849) indica que "...En las afueras de la población se encuentran 2 ermitas (...) otra al Este que fue de San isidro y que solo conserva las paredes..." (Fig. 3).

En un área contigua a la edificación emergen una serie de afloramientos de gneis que constituyen el verdadero tesoro de la zona, al ser los depositarios de los numerosos grabados al aire libre.

La estación rupestre se integra en la comarca de Santa María la Real de Nieva, región situada al Sureste de la depresión del Duero, en donde emergen los depósitos terciarios que rellenan esta fosa, y sobre los que se localizan materiales cuaternarios.

La totalidad del macizo de Santa María la Real de Nieva comprende algo más de doscientos kilómetros cuadrados, hallándose compuesto por diferentes tipos de rocas, graníticas hercínicas, filonianas y metamórficas, así como rocas sedimentarias detríticas y químicas, cuyos períodos de formación se hallan comprendidos en torno a los seiscientos millones y quinientos mil años.

La gran acumulación de rocas que poseen cualidades pizarrosas contribuyeron a la creación de una industria en torno a ellas desde principios del siglo pasado, continuán-

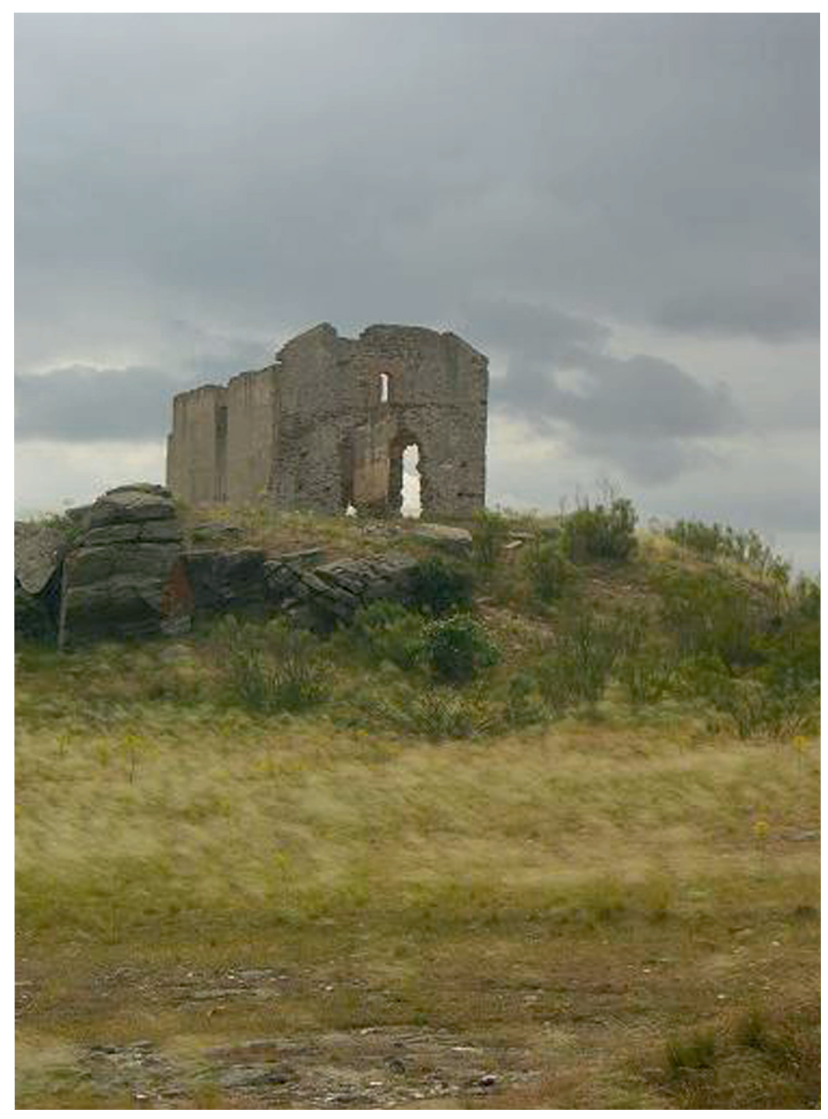

^ Figura 3. Ábside de la ermita de San Isidro. Domingo García (Segovia). Vista desde el Este. Foto H. Pecci. dose en la región su trabajo incluso en la actualidad de forma muy asidua.

La comarca, del mismo nombre, posee altitudes desde casi mil metros sobre el nivel del mar hasta los setecientos ochenta que se localizan en el río Eresma, al norte de Bernardos, siendo las zonas más altas Cuesta Grande, con novecientos ochenta y seis metros, y Carbonero, que cuenta con novecientos sesenta y nueve metros, además de otras elevaciones en torno a los $900 \mathrm{~m}$ que se sitúan en una alineación Noreste-Sureste desde Bernardos hasta la misma localidad de Santa María la Real de Nieva.

Un fenómeno interesante sufrido en este territorio estuvo formado por las conocidas como "arenas voladoras", agente destacado en los procesos erosivos y de moldeado del paisaje, teniendo un protagonismo especial en el Cerro de San Isidro, ya que al situarse a mayor altura que el resto del territorio, sufrió de forma más asidua estos embates.

Sin embargo, estos fenómenos tuvieron un aportación positiva, ya que contribuyeron a una primera separación entre los grabados "...el pseudobarniz del desierto que cubre los petroglifos paleolíticos (y no los históricos) se relaciona con el pulido por la actividad eólica de la Tierra de Pinares durante el Dryas reciente (entre hace 12.500 y 11.000 años)..." (Díez Herrero y Martín-Duque 2005).

De esta manera, se llevó a cabo un proceso de selección de las rocas, puesto que se aprecia como las que poseen un mayor bruñido fueron las elegidas para servir como soporte a las representaciones artísticas.

Desde la cima del Cerro de San Isidro se otea al Norte, hasta donde llega la vista, la Tierra de Pinares, mientras que en el sur emerge la Campiña Segoviana. En estas tierras se alzan pequeños municipios en los que se pueden descubrir diferentes muestras de arte rupestre, compartiendo todos ellos una misma época de fundación, más o menos durante el mismo período de tiempo, hacia los siglos XI/XII.

Así, Bernardos surge a tres kilómetros de distancia aproximadamente de Domingo García en dirección Noreste; en la misma dirección asoma Migueláñez, pero más o menos a un kilómetro y medio; en sentido opuesto, a unos tres kilómetros y medio de marcha en dirección Suroeste, se asienta Ortigosa del Pestaño, y con escasa diferencia, pero hacia el Sureste se avista Miguelibáñez.

No obstante, el punto central, poseedor de la mayor aglomeración de grabados, y en torno al cual se llevan a cabo las líneas de investigación y es el objeto de estudio, se encuadra dentro de la elevación de Cuesta Grande.

\section{ANTECEDENTES DEL YACIMIENTO}

En 1992 se anunciaba el descubrimiento del conjunto de arte rupestre al aire libre de Domingo García, Segovia, del que forma parte El Cerro de San Isidro, también conocido 
como Cuesta Grande, y en donde aparecen representaciones datadas, en un principio, en momentos paleolíticos, junto a otras figuras de cronología postpaleolítica.

Las primeras informaciones sobre el Cerro de San Isidro las expone Tuñón Mallada (1929), si bien, el claro conocimiento sobre la estación se produce cuando el Comandante de Artillería F. Gonzalo Quintanilla (1970) describe las insculturas o figuras halladas, dando una datación paleolítica al caballo piqueteado que sería el grabado más llamativo, cronología que once años después E. Martín y A. Moure (1981) concretarian aún más, estableciendo su creación en momentos avanzados solutrenses.

A partir del escrito realizado por Gonzalo Quintanilla, la estación comienza a ser estudiada por otros investigadores, como los citados E. Martín y A. Moure, Lucas de Viñas (1971) o Lucas Pellicer (1973). Durante la realización de estos trabajos de investigación se alude a la estación como una concentración de representaciones de gran homogeneidad, integrada por grabados de arte rupestre esquemático en los que sobresalen tres horizontes artísticos: esquemático, escenográfico y un tercero que podría ser medieval.

En estos tres ciclos gráficos se dejan ver, junto al resto de las figuras, diferentes signos cruciformes, lo que dio pie a algunos investigadores a especular con la posible existencia de un lugar de culto (Gómez-Barrera 1993), donde se llevarían a cabo diferentes rituales, y, si bien, no se podría conocer el sentido de estas ceremonias, algunas teorías apuntarian a variados tipos de liturgias astronómicas, quizás protohistóricas, aunque es extraño que tratándose de un lugar sacro, las figuras se encontraran tan expandidas en el terreno sin hallarse vestigios de un centro neurálgico, además de no descubrirse ningún tipo de representaciones de un ídolo o divinidad tutelar.

De todos modos, ciertos investigadores consideran que la existencia de cruces en las estaciones de arte rupestre lo único que explica es la perduración en el tiempo de esta clase de signos (Gómez-Barrera 1993), pudiendo tratarse de marcas de algún tipo, imposibles de interpretar en la actualidad.

No obstante, la tipología de las figuras cruciformes cristianas y medievales es bastante apreciable con respecto a las representaciones de épocas anteriores, por lo que en muchas ocasiones se puede datar, sin excesivos contratiempos, en momentos posteriores al I milenio a. C.

Tiempo más tarde, E. Ripoll, A. Moure y R. Balbín llevarian a cabo un nuevo estudio en 1982, para, posteriormente, durante la segunda mitad de los años ochenta, ser el Doctor Eduardo Ripoll Perelló el que prosiguiera con la exploración de la zona, llevando a cabo una serie de análisis y observaciones que constarian de dos períodos de investigación bien definidos, centrados fundamentalmente en los grabados rupestres localizados en el Cerro que de San Isidro.

Un primer estudio, formado por los trabajos de planimetria y topografia, en donde se localizaron y documen- taron cincuenta y ocho afloramientos rocosos con paneles grabados, procediéndose a su numeración y localización en los planos, mientras que, paralelamente, se efectuaban los calcos directos, así como la recogida de información a través de la documentación fotográfica.

Las operaciones emprendidas tuvieron sus frutos, ya que con esta serie de acciones se consiguieron localizar mil quinientas figuras postpaleolíticas.

La segunda parte de estos trabajos se dirigieron primordialmente a la puesta en valor y el estado de conservación de los paneles y sus representaciones.

Ya, en los años noventa Sergio Ripoll López y Luciano José Municio fueron los encargados de continuar los trabajos de investigación del Cerro de San Isidro, labor que sería recogida en diferentes escritos entre los años 1992 y 1994, para, al final de esta década recopilarse los últimos estudios y publicaciones efectuados sobre los grabados rupestres de Domingo García en las memorias que llevan como título "Domingo García. Arte rupestre Paleolítico al aire libre en la meseta castellana. Arqueología en Castilla y León. Junta de Castilla y León. Consejería de Educación y Cultura".

\section{GRABADOS RUPESTRES}

Tras abandonar Santa María la Real de Nieva, circulando por la carretera SG-P-3411, a unos dos kilómetros de distancia se asienta Ortigosa del Pestaño, pequeña localidad de menos de cien habitantes que se deja pronto atrás, para, pasados unos segundos, advertir, observar, como poco a poco se recorta, paulatinamente, pausadamente, la silueta de la Ermita de San Isidro, hasta hacerse totalmente visible en el horizonte.

Recorriendo unos kilómetros más, la vía se bifurca, emergiendo en la parte izquierda la carretera SG-V-3414, y desde ella un pequeño camino de tierra que nos lleva a la zona más alta del Cerro de San Isidro.

Es aquí, frente a la Ermita, donde se disponen los afloramientos de las grandes rocas que sirven de soporte a los grabados, muchos de ellos actualmente desaparecidos por efecto de la acción humana, consecuencias que se hacen patentes nada más llegar al cerro.

La actividad de las canteras, explotadas de forma intensiva a partir del siglo XVI, no han dejado "roca sobre roca" allá donde han operado. Esta situación ya era denunciada por Sergio Ripoll y Luciano José Municio (1992) además de ser revelada por Eduardo Ripoll Perelló, cuando en octubre de 1992 remitía una comunicación a la Consejería de Cultura de la Junta de Castilla y León alertando sobre el escenario existente en ese momento "...Ahora está todo aquello convertido en un coto de caza y la Zona Alta parece que haya sido escenario de una batalla a causa de los destrozos de las canteras...". La opinión del profesor era 
refrendada por diversos periódicos, que se hacian eco de la pérdida cultural que podían provocar estos destrozos "Voladura en Domingo García de un panel prehistórico (EI Adelantado de Segovia, martes, 18 de febrero de 1992)" "Aparecen en Segovia un centenar más de nuevas pinturas rupestres del Paleolítico (...) El año pasado, el juzgado de instrucción de Santa María de Nieva inició la investigación de la destrucción de uno de los petroglifos, debida presumiblemente a las voladuras que se realizan en una cantera próxima dedicada a la extracción de pizarra...(El País, jueves, 12 de agosto de 1993)".

Pero los grabados no sólo están amenazados por esta ocupación industrial, asimismo tienen que hacer frente a otro desafío que, si bien es de menor envergadura, no por ello deja de ser menos importante, puesto que gradualmente va hiriendo y socavando la propia existencia de la estación de arte rupestre; se trata de los actos vandálicos que han llevado a la destrucción de muchos paneles, practicando graffitis, grabando sobre ellos iniciales u otras figuras, e incluso siendo arrancados para ser instalados en las fachadas de algunas casas del mismo municipio de Domingo García.

Sea como fuere, las representaciones se localizan en una amplia zona del cerro, cincelada sobre numerosas rocas y orientadas hacia el Sur y el Sureste fundamentalmente, quizás como protección de los rigores climatológicos (Ripoll y Municio 1999), o posiblemente debido a la mayor luminosidad existente en esta zona.

Las técnicas básicas utilizadas para esculpir las piezas han sido esencialmente dos, la incisión por medio de un objeto puntiagudo, manifestada fundamentalmente en los grabados de estilo paleolítico, exceptuando la figura quizás más conocida del Cerro de San Isidro, el gran caballo de más de un metro de distancia y más de cincuenta centímetros de altura, donde es visible el uso del segundo método en el trabajo de piqueteado efectuado, y cuyas impresiones constituyen la silueta del équido.

El manejo y ejecución del piqueteado se observa sobre todo en los grabados realizados en los momentos que recoge el arte denominado "postpaleolitico", si bien, la técnica es totalmente diferente a la plasmada en el gran cuadrúpedo, ya que si en éste únicamente se marcó el contorno, en la totalidad de las representaciones el "punteado" cubre el conjunto de la figura de forma muy homogénea, hecho que evidencia una única aplicación.

De esta forma, el autor actuó sobre la roca sin esbozar previamente la figura, o bien marcando la figura con un componente que fuera fácil de eliminar, suposición apoyada en el hecho de no haberse localizado ningún rastro de pintura ni de color, teniendo una idea muy clara de la representación que iba a efectuar sin necesidad de tener que proyectarla, por lo que no gozaba de ningún margen de error en la ejecución, ya que algún fallo podría descartarla totalmente si no se adecuaba al resultado final buscado.
No obstante, un estudio más detenido del caballo ha logrado localizar pequeñas incisiones bajo las marcas de piqueteado (Ripoll y Municio 1999), lo que supondría una labor previa de trazado de la figura, para en momentos siguientes, proceder a su piqueteado.

Por tanto, en Domingo García nos encontramos con el uso de dos técnicas fundamentales de ejecución de los grabados, las cuales pertenecen a momentos cronológicos distintos, pero también nos hallamos ante diferentes "estilos" de arte, que, de igual forma, corresponden a épocas dispares.

Así, las representaciones paleolíticas se emplazan claramente en los últimos períodos de esta etapa, es decir, fin del Solutrense Superior y principios de la fase Magdaleniense, relacionándose directamente con las estaciones al aire libre de Siega Verde (Salamanca) y Foz Côa (Portugal) (Beltrán 1996) a través de las técnicas utilizadas y las imágenes recogidas y congeladas en el tiempo, équidos, cérvidos, bóvidos, etc., especies en algunos casos ya desaparecidas, que muestran la fauna característica existente en este período concreto, en el que estos animales son un factor esencial como fuente de alimentación, además de constituirse en un hito de datación.

El problema se plantea con el intento de delimitar la época, fijar la fecha en que se han plasmado los centenares de figuras postpaleolíticas, escenas de caza, bailes, combates, figuras de guerreros, etc., ya que no revelan unas particularidades precisas para adscribirlas a un género artístico concreto, dando la sensación de poseer la misma autoría, de disfrutar de un mismo ciclo de creación.

A esta situación se añaden otra serie de obstáculos que impiden emplazar las representaciones en una etapa precisa, pues no se ha localizado en los paneles ningún rastro de pigmentación que pudiera ser susceptible de datación; al mismo tiempo, la estación de arte rupestre no se relaciona con ningún estrato que pudiera desvelar una fecha relativa, y tampoco se puede vincular a algún yacimiento arqueológico cercano.

A causa de todo ello, numerosos investigadores incluyen los grabados dentro de un grupo calificado como "arte pastoril" (Gómez-Barrera 1991), de trazos infantiles y no sujeto a una época especifica, surgido en diferentes etapas, sin poseer un conjunto de características que pudieran fijar una tendencia artística determinada.

\section{CRONOLOGÍA}

Vistas las inmensas dificultades existentes y la carencia de elementos idóneos capaces de contener una minima información que ayude a situar en un espacio temporal la estación de Domingo Garcia, en contraposición con el arte en cuevas, el cual puede inscribirse en una fase definida gracias a los diferentes hallazgos o yacimientos que pueden 
localizarse en su interior, diversos estudios han recurrido a distintos métodos de investigación, bien buscando ciertos paralelismos con otros yacimientos de arte rupestre, o bien efectuando algún que otro análisis, tomando como base procedimientos técnicos diferentes a los empleados usualmente.

El cerro de San Isidro alcanza una altitud de 986 metros aproximadamente sobre el nivel del mar, sobresaliendo de la Ilanura circundante lo suficiente para que las corrientes que transportaban las micropartículas de arena, las "arenas voladoras", fueran lo bastante incisivas para pulir y suavizar los planos orientados hacia el Sureste, sobre los que el viento ha actuado principalmente.

Este bruñido se ha utilizado como un primer hito cronológico para las representaciones paleolíticas, puesto que sus autores han trabajado fundamentalmente sobre sus paredes, de esta suerte, que Carlos Martín Escorza afirma que el gran caballo piqueteado posiblemente se esculpió entre dos períodos de vientos o Fases Eólicas (Martín-Escorza 2006), ya que se trazó en una superficie pulida, la cual, posteriormente sufrió de nuevo las acometidas del viento, mostrando sus contornos la misma tonalidad que la roca madre.

Al tallarse las figuras, su interior descubría una pátina distinta a la superficie, hecho que se interpretó como una posibilidad para obtener dataciones que situaran la estación en un contexto cronológico claro.

La base de este método es relativamente simple; al practicarse el piqueteado e ir labrándose poco a poco la imagen, se descubría un color amarillento claro que lo diferenciaba claramente del resto del panel.

Una vez configurada totalmente la representación, la tonalidad iba ensombreciéndose según transcurría el tiempo, por lo que las figuras más antiguas y las más modernas presentan distinta pátina, de tal forma que se puede establecer una seriación relativa de antigüedad.
Sin embargo, este procedimiento presenta algunos inconvenientes, ya que únicamente se tiene en cuenta el paso del tiempo, sin considerar, en muchos casos, aspectos tan importantes como la incidencia de algunos factores externos, aparición de líquenes, exposición directa al sol, lluvia, acción antrópica, etc., por lo que su actividad en ocasiones produce que grabados de un mismo "estilo" presenten una pátina diferente, y representaciones de, en teoría, diferentes edades presenten la misma tonalidad, hecho contrastable en la inmensa mayoría de los paneles de Domingo García, en donde es visible que figuras que comparte un mismo espacio de tiempo presentan un fondo de diferente matiz, de tal forma, que en un panel aparecen jinetes con una factura semejante pero con otra tonalidad (Fig. 4).

A ello se suma el hecho de que en algunos casos no hay una diferencia visible entre los grabados y la superficie del panel en el que se asientan (Ungé Plaja et al. 2001) puesto que exteriorizan la misma pátina, lo que hace que este medio no pueda ser considerado como un método preciso, ya que a través de él se puede conocer exclusivamente, y no siempre, la antigüedad relativa de las representaciones.

Ante la imposibilidad de alcanzar un resultado determinado, imposible de averiguar a través de la datación relativa, se ha recurrido a otros sistemas cronológicos en la búsqueda del mayor acercamiento al origen del arte rupestre al aire libre (Fig. 5).

Para ello se acudió a otros procedimientos basados en la datación directa sobre los grabados, como la espectrometría de masas con aceleradores (AMS) o el método de microerosión.

En principio el AMS no precisa de grandes muestras para su análisis, utilizándose en arte que es susceptible de contener algún tipo de materia orgánica, como el pigmento de las pinturas rupestres, o algún resto que se localiza en la superficie en que éstas se llevaron a cabo.

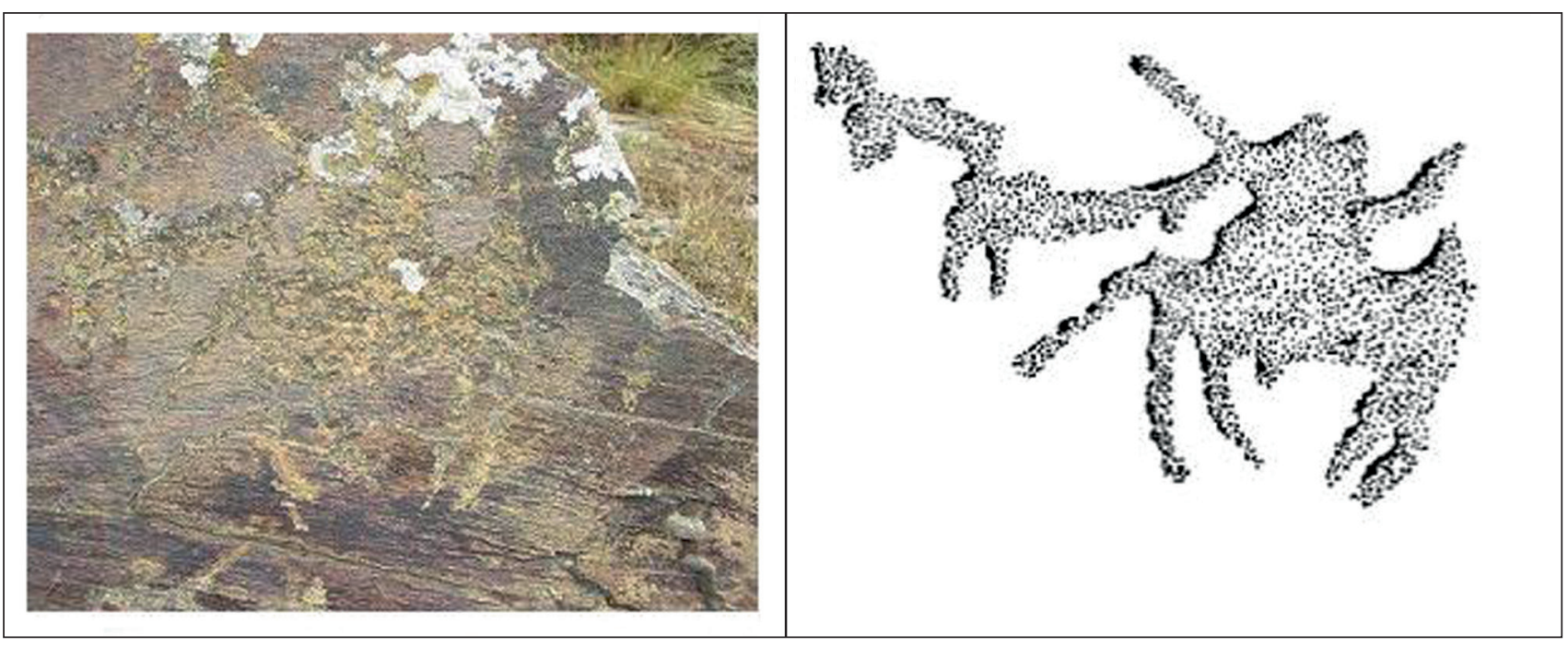

A Figura 4. Representación del jinete 23 del Panel 9 j. Foto E. Ripoll. 


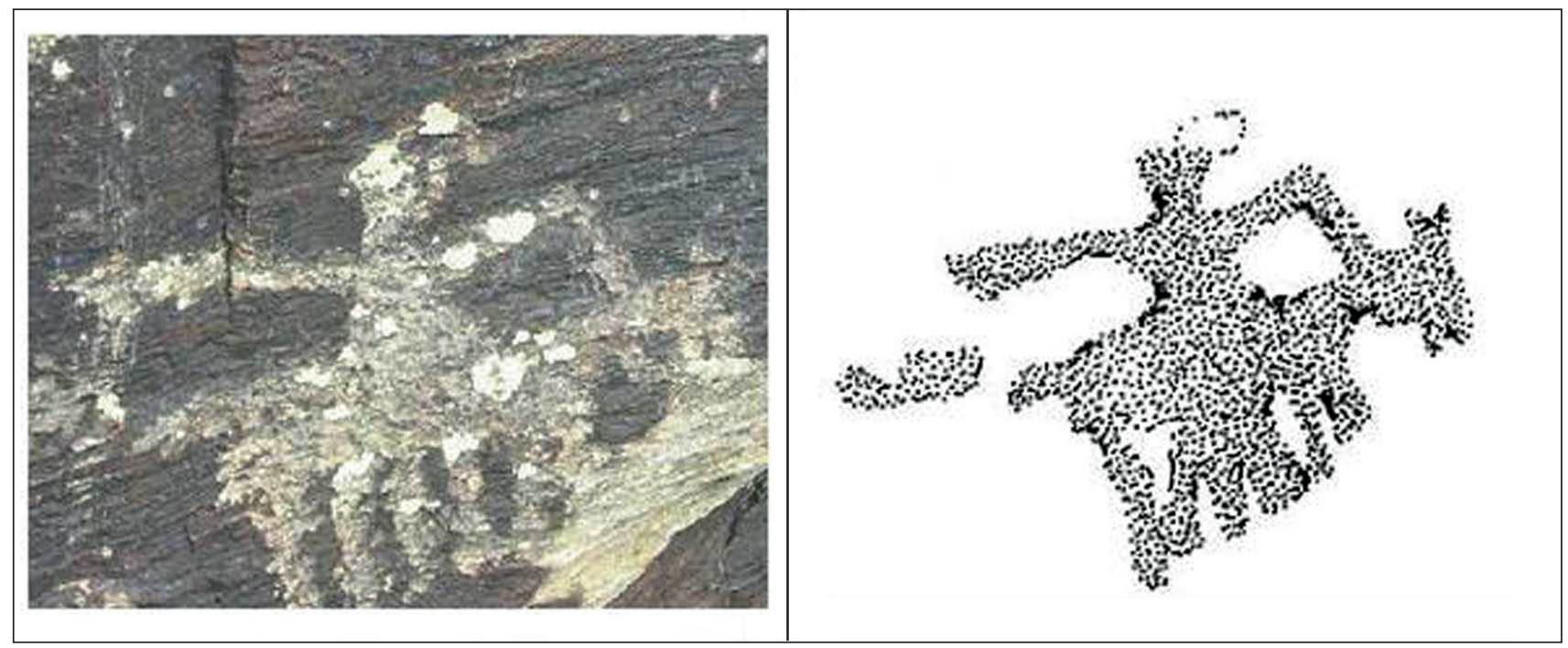

A Figura 5. Representación del jinete 23 del Panel 26 i. Foto H. Pecci.

Sin embargo, la puesta en marcha de este método tiene, cuanto menos, un mayor plus de dificultad a la hora de ponerlo en práctica sobre escenarios en los que no se localiza ningún resto de material orgánico, caso de los grabados. No obstante, esta situación no ha sido óbice para ensayar sobre diferentes paneles tallados, tomando como base las acumulaciones de partículas que se depositan en el interior de los grabados por efectos de la lluvia, las cuales constituirian una suave película en la que se atrapan diferentes partículas, como si de insectos en el ámbar se trataran, perviviendo en el tiempo, para dar una fecha cercana a la creación de esta capa.

A esta técnica se une un segundo procedimiento utilizado, la micro-erosión, desarrollado por Robert Bednarik que consiste, en palabras de Antonio Beltrán Martínez "... el método de "micro-erosión de las rocas" puede sintetizarse en que al realizar los grabados quedan granos cristalinos de aristas vivas, por ejemplo de cuarzo, que con el paso del tiempo se desgastan cada vez más redondeados y si en la misma roca u otra próxima hay otro grabado de fecha conocida, comparando unos y otros trazos, por medio de lo que el autor llama "calibración", es posible fechar el de data desconocida; el autor advierte que tal método no es aplicable a las rocas de fácil exfoliación..." (Beltrán 1996).

Ambos sistemas de datación se emplearon a mediados de la década de los noventa del siglo XX en la recién descubierta estación de grabados de Foz Côa (Portugal).

En julio de 1995 se presentaba un informe, elaborado por Robert Bednarik y Alan Watchman, en donde se exponían los resultados obtenidos por AMS y micro-erosión, los cuales pusieron en pie de guerra a la comunidad arqueológica portuguesa, ya que se dudaba de la antigüedad de los hallazgos, puesto que se indicaba que los grabados más lejanos en el tiempo abarcaban entre 10000 y 6000 años como mucho, ubicando los más modernos en no más de cien años.
Este ambiente se enrarecía aún más cuando Robert Bednarik, daba una nueva vuelta de tuerca, aseverando la imposibilidad de que los yacimientos con arte localizados por esas fechas en la Península lbérica tuvieran dataciones paleolíticas (Chapa 2000), pues no habrían aguantado el paso del tiempo; e incluso ha cuestionado la veracidad del arte rupestre paleolítico de Alemania, argumentos, todos ellos, que continúa defendiendo en la actualidad.

Por su parte, los resultados de Alan Watchman, eran, si cabe, todavía más sorprendentes, ya que situaba la distancia cronológica de los grabados en mil setecientos años, gozando los más modernos de un siglo aproximadamente.

Este investigador realizaria en 1996 varias pruebas y cálculos preliminares en dos zonas concretas de la estación de Domingo García. Los resultados aproximados fueron un tanto peculiares, ya que de las doce figuras seleccionadas, la más lejana en el tiempo, un antropomorfo con los brazos en las caderas, se habria labrado en 1493 aproximadamente (Fig. 6), mientras que la más reciente, un posible guerrero con escudo situado en el sector de Las Canteras, contaba con poco más de un siglo, siendo creada más o menos en 1902.

Vistos los resultados obtenidos en la búsqueda de una cronología más o menos plausible para la fase escenográfica del Cerro de San Isidro, los movimientos llevaron a adoptar otras formas de poner "edad" al arte de Domingo García. En un nuevo intento de datación, se acudió a un fórmula basada en un principio básico de la estratigrafia, la Ley de la Superposición, definida por el danés Nicolás Steno (16381686), conocido como el padre de la Geología, por la que "En una secuencia no deformada de rocas sedimentarias, cada estrato es más antiguo que el que tiene por encima y más moderno que el que tiene por debajo".

De este modo, se aprovechaba este razonamiento para emplearlo en las superposiciones existentes en los paneles de grabados de Domingo García. Con todo, como se compro- 
baría posteriormente, el resultado obtenido no fue muy satisfactorio, ya que las figuras que se mostraban sobrepuestas poseían trazas o diseños análogos, muy semejantes entre sí, lo que evidenciaba que su manufactura no debía hallarse muy alejada en el tiempo.

Hasta ahora, los recursos puestos en marcha con el objetivo de adquirir nuevos datos que nos aporten un mayor conocimiento de los grabados de Domingo García no han sido suficientes, por lo que avanzamos poco a poco en la consecución de resultados, planteando las investigaciones en el propio seno de los paneles, es decir, estudiando las escenas mismas con el fin de obtener la mayor cantidad de datos posibles que ayuden a esclarecer las incógnitas que se ciernen sobre ellos.

A pesar de las dificultades que provoca la obtención de datos, defendemos la proposición que postula la existencia de dos horizontes culturales, una fase de estilo paleolítico bien definida y una etapa escenográfica, que se localizaría dentro de un mismo momento cronológico, y en donde se plasman acontecimientos narrativos, relatando algún tipo de episodio o suceso, posiblemente contemplado directamente por el autor o autores de estos paneles.

En este último estadio surgen ciertas figuras, en un número reducido, que presentan rasgos esquemáticos, si bien, nada indica que no sean coetáneas al resto de los grabados, ya que varias de ellas comparten escena con el resto de grabados, presentando la misma pátina.

Aparte de ello, tal y como asevera Antonio Beltrán Martínez, el "arte esquemático" no es un arte unificado, por lo que no se puede convertir en un indicador cronológico, ya que es susceptible de aparecer en otras etapas que no po- seen fechas del Calcolítico o Bronce, es decir de la etapa "esquemática". Así, tenemos algunos ejemplos dentro del arte paleolítico, donde afloran multitud de símbolos abstractos y líneas similares a este estilo, o en momentos históricos, en que igualmente emergen tipos con estas particularidades.

Igualmente, existen otros puntos para apoyarse en esta idea, ya que en Domingo García apenas aparecen tectiformes, herraduras, retículas, cazoletas, serpentiformes, ancoriformes, barras, ídolos, zig-zags, o motivos abstractos de carácter geométrico, y sólo en algún panel surge algún grabado similar, si bien, se encuentran contiguos a jinetes, formando parte de la escena y presentando el mismo color de pátina.

Por tanto, las dificultades de la data en Domingo García son obvias, de modo que hay que centrarse en los objetos que puedan ser susceptibles de suministrar alguna información, prendas, armas, caballos, etc., hasta despejar el camino hacia la recuperación de información que pueda situar los grabados en su contexto cronológico e histórico.

En este estado de cosas, ciertas representaciones pueden servir de punto de salida cronológico, como podría ser, por ejemplo, el considerable número de jinetes que se personifican por doquier, los cuales constituyen una primera señal para apuntar que nos encontramos ante una etapa no anterior al siglo VIII a. C., puesto que los indicios de monta no se documentan en la Península Ibérica antes de estas fechas, explotándose el caballo originalmente como fuente de alimento, para, posteriormente, convertirse en animal de tiro, testimonio éste recogido y expresado tanto en la iconografía como en las estelas del Bronce Final y de la Primera Edad del Hierro.

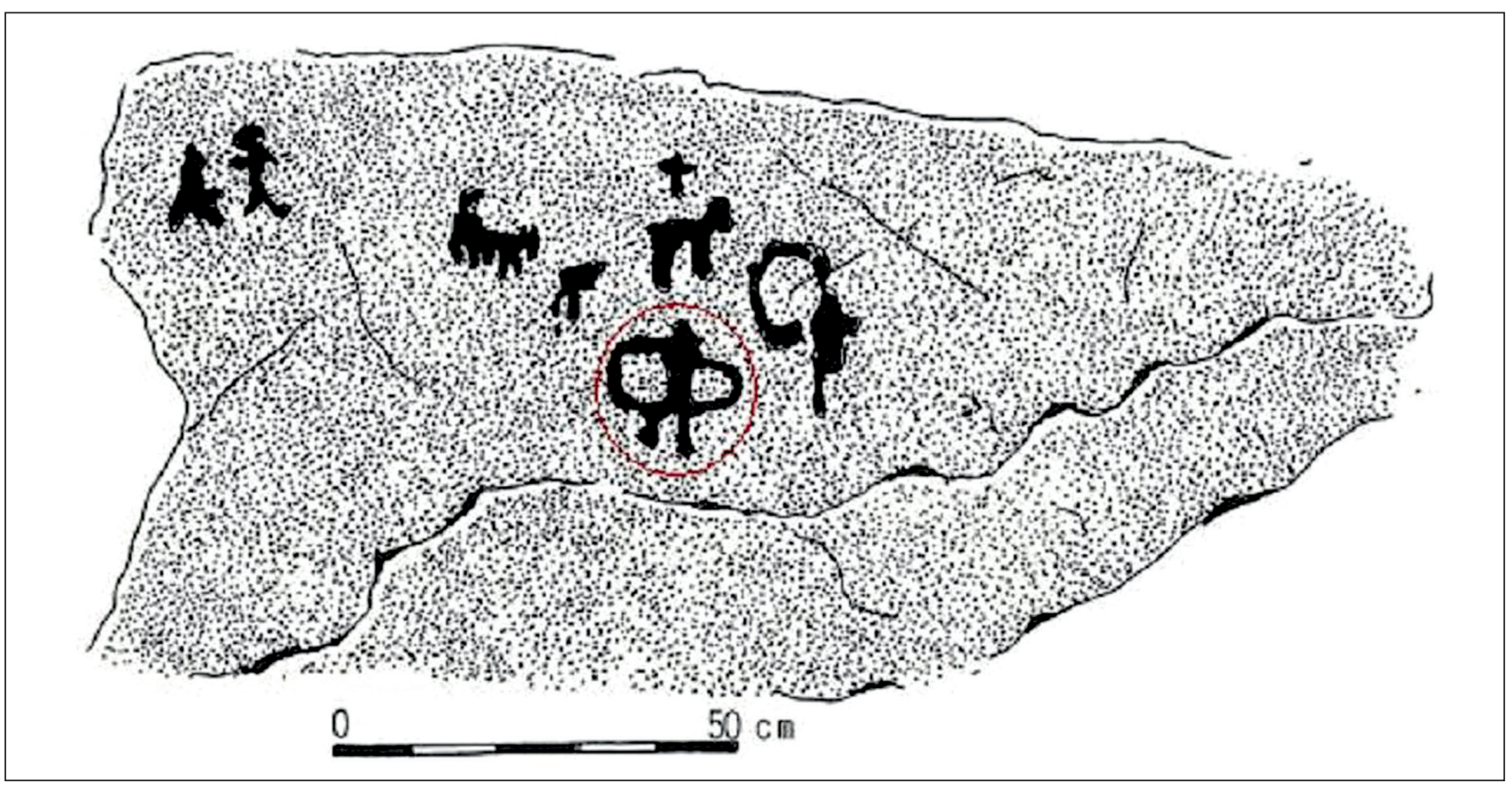

$\Delta$ Figura 6. Panel 9 d. Figuras 1 a 6. E. Ripoll. 


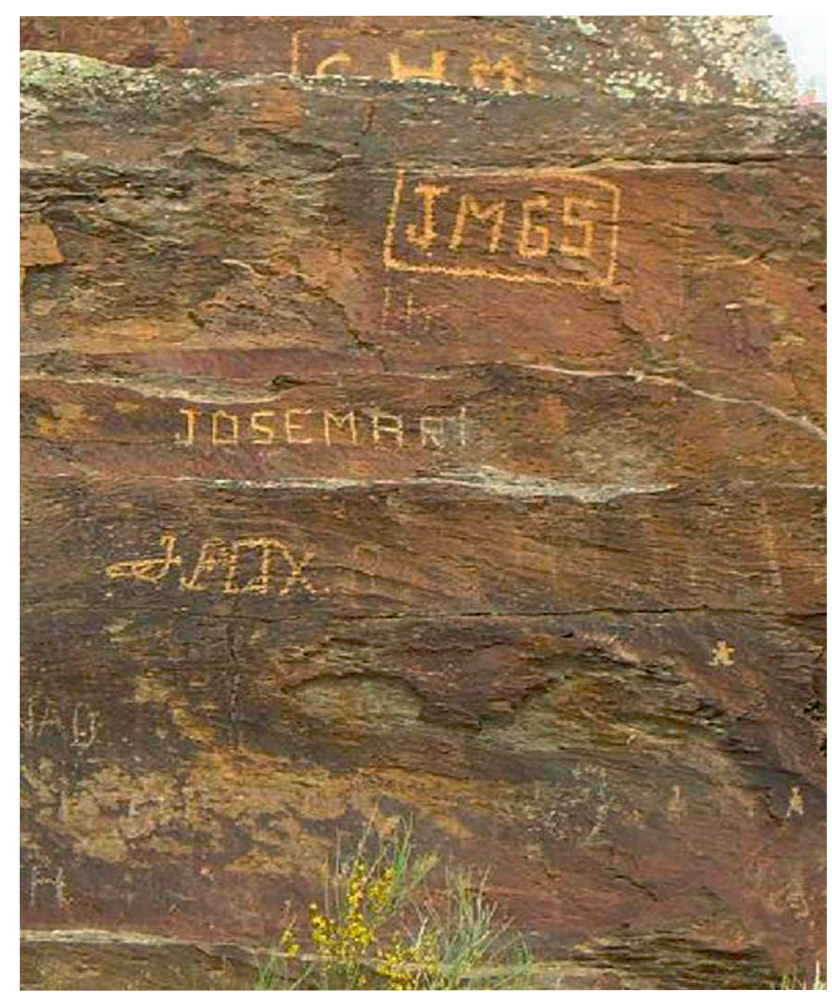

- Figura 7. Destrucción de arte causado por graffitis modernos. Foto H. Pecci.

La única excepción apta para oponerse a esta aserción, de momento, sería la figura de un jinete plasmado en el abrigo X del Cingle de La Gallusa (Castellón), atribuido al arte levantino, aunque presenta numerosas dudas, ya que existen opiniones que hablan de las mismas fechas del siglo VIII a. C. para su ejecución, e incluso de haber sido víctima de manipulaciones posteriores, "...y quizás, el caso más llamativo, sea el del jinete del Abrigo X de la Gasulla (Ares del Maestrat, Castellón), interpretado como tal al no tenerse en cuenta que las formas pintadas fueron modificadas con una acción de raspado y grabado muy posteriores, de manera que lo resultante nada tiene que ver con lo que originariamente se pintó..."(Alonso y Grimal 2008), poniendo en tela de juicio la confirmación de fechas tan tempranas para la monta en la Península.

Existe otra posible iconografía, supuestamente la figura de un elefante (Corchón et al. 1989), cuya presencia en los paneles situaría la estación de Domingo García en unas fechas del último cuarto del siglo III a. C., durante las campañas de Anibal contra Helmantica (Salamanca) y Arbucala (Toro).

Con todo, parece ser que las rutas que siguió el ejército cartaginés para penetrar en la Meseta Norte se encuentran un tanto alejadas de Domingo Garcia, pues el recorrido más aceptado en el avance de las fuerzas cartaginesas (Sánchez Moreno 2000) arrancaría en Qart Hadasht (Cartagena), para desplazarse cerca de Sierra Morena hasta llegar a Mérida, y desde aquí, marchar por lo que en tiempos posteriores comprendería la Vía de la Plata, vadeando el Tajo, y, a continuación atravesar la Sierra de Gredos, hasta arribar primero Helmantica (Salamanca), y posteriormente avanzar hacia Zamora y asediar Arbucala.

El repliegue de las tropas púnicas se llevo a cabo siguiendo la dirección Noroeste/Sureste, a través de la Sierra de Gredos, siendo atacado en tierras carpetanas por olcades, carpetanos y la población superviviente de Helmántica cuando se disponía a cruzar el Tajo.

Tampoco hay que olvidar que, aunque los proboscidios no son una especie endémica de la Península Ibérica, ya se tenía conocimiento de su existencia, no sólo durante la época prerromana, sino también en etapas posteriores, como lo demuestran diferentes ejemplos de reproducciones de este animal, sea la pintura de un elefante de combate proveniente de la Ermita de San Baudelio de Berlanga ( $\mathrm{Ca}-$ sillas de Berlanga, Soria), datada en el siglo XI, o la imagen que aparece en la portada de Santa María la Real de Olite (Navarra), con fechas del siglo XIII.

No se deben finalizar estas líneas sin hacer referencia a un conglomerado, que, aunque nada tiene que ver con los estilos que se revelan en los paneles de Domingo García, poseen gran trascendencia pos sí mismos, no por su valor artístico, sino por el deterioro que provoca su manufactura; son los grabados modernos, graffitis (Fig. 7), fechas, añadidos a figuras, etc., totalmente nocivos para la estación de arte, ya que están destrozando todas las representaciones anteriores sin posibilidad de recuperación, peligrando el conjunto de los grabados, al mismo tiempo que suponen una seria amenaza, ya que los condena a su más que probable desaparición.

\section{CONCLUSIONES}

Tras haber retomado las investigaciones de los grabados al aire libre de Domingo García, gradualmente nos vamos acercando al fondo de la cuestión. En consecuencia, paso a paso, paulatinamente, vamos conformando un corpus que será la base de todo nuestro estudio.

A lo largo de estas líneas hemos reunido y presentado una serie de afirmaciones que pueden ayudarnos a delimitar nuestra zona de acción, hasta alcanzar nuestros objetivos fundamentales:

1. Las representaciones presentes en Domingo García pertenecen a dos horizontes culturales, una primera fase de "estilo Paleolítico" y una segunda etapa, sin percepción cronológica clara, que es denominada por diferentes investigadores "fase escenográfica", estando integrada por todos los grabados postpaleolíticos, sin ninguna separación o distinción. 
2. Las figuras presentan dos técnicas, incisión y piqueteado, y parece ser que no se esbozaban, ejecutándose de forma directa, o bien marcándose con un colorante fácil de eliminar, pues no se han localizado restos de pintura.

3. Aparece un número muy reducido de figuras que presentan algunos rasgos esquemáticos, aunque no existen indicios para esgrimir una datación diferente al resto, puesto que comparten e integran diferentes escenas y exhiben el mismo color de pátina, así como trazos muy similares al resto de los grabados.

4. Apenas aparecen rasgos tan característicos del "arte esquemático" como pueden ser tectiformes, herraduras, retículas, cazoletas, serpentiformes, ancoriformes, barras, ídolos, zig-zags, o motivos abstractos de carácter geométrico.

5. La pátina presente en los paneles no es representativa como método de datación, ya que únicamente puede hacer referencia a la anterioridad o posterioridad de una imagen sobre otra, y no de forma muy clara, ya que, en algunos casos, representaciones de un mismo período presentan diferentes tonalidades debido, en muchos casos, a la acción climá- tica, líquenes, animales, hombres, etc., si bien, los trazados constatan un mismo período de ejecución.

6. Exámenes realizados con distintas técnicas de datación han dado resultados, cuanto menos sorprendentes, situando las fechas en los últimos cinco siglos del segundo milenio.

7. El estudio de superposiciones existentes en los paneles no ha proyectado ningún resultado concreto, ya que los trazos y diseños examinados son muy semejantes, ofreciendo el mismo tipo de manufactura, hecho que deja traslucir una ejecución muy cercana en el tiempo.

8. Algunos temas representados facilitan una aproximación cronológica, caso de la monta de caballo, no anterior en la Península Ibérica al siglo VIII a. C., o la aparición de un supuesto "elefante" con fechas del siglo III a. C., en su último cuarto, si bien, pudiéndose desplazar a tiempos posteriores.

Todos estos resultados están sujetos a los avances y evolución de los trabajos de investigación, por lo que, obviamente, son susceptibles de recibir modificaciones y variaciones en muchos de sus contenidos, si bien, el esqueleto básicamente es el propuesto en este escrito.

\section{BIBLIOGRAFÍA}

AcostA, P. 1983: "Técnica, estilo, temática y tipología en la pintura rupestre esquemática hispana". Zephyrus: Revista de Prehistoria y Arqueología 36: 13-25.

Balbin Behrmann, R., Moure Romanillo, J. A. 1998: "El arte rupestre de Domingo García (Segovia)". Revista de Arqueología IX: 16-24.

BEDNARIK, R. G. 2003: "The earliest evidence of paleoart". Rock Art Research 20: 89-135.

Beltrán Martinez, A. 1989: "Digresiones sobre el arte esquemático de aspecto prehistórico y sus versiones medievales y modernas: Problemas de método". Aragón en la Edad Media. Estudios de Economía y Sociedad: 97-111.

- 1983: "El arte esquemático en la Península Ibérica: Orígenes e interrelación. Bases para un debate". Zephyrus XXXVI: 37-41.

- 1996: "La datación de los grabados de Foz Do Côa, en Portugal y la importancia del yacimiento: Síntesis de una polémica y planteamientos". En Maciel, M. Justino (coord.): Miscellanea em homenagem ao professor Bairrão Oleiro. Edições Colibri. Lisboa: 45-54.

BLÁzouEz, J. M. 2001: "Las guerras en Hispania y su importancia para la carrera militar de Anibal, de Escipión el Africano, de Mario, de Cn. Pompeyo, de Sertorio, de Afranio, de Terencio Varrón, de Julio César y de Augusto". Aqvila Legionis 1: 1-54.

CoRCHÓN, S., LUCAS, R., GonZÁleZ-TABLAS, F., BÉCARES, J. 1988: "El arte rupestre prehistórico en la región castellano-leonesa (España)". Zephyrus: Revista de Prehistoria y Arqueología 41-42: 7-18.

ChAPA BRUnet, T. 2000: "Nuevas tendencias en el estudio del Arte Prehistórico". ArqueoWeb - http://www.ucm.es/info/arqueoweb - 2(3) diciembre.

Diez Herrero, A., Martin-Duque, J. F. 2005: Las raíces del paisaje. Condicionantes geológicos del territorio de Segovia. Colección Hombre y Naturaleza. Junta de Castilla y León. Salamanca.

Gómez-Barrera, J. A. 1991: "Contribución al estudio de los grabados rupestres postpaleolíticos de la Península Ibérica". Espacio, Tiempo y Forma, Serie I, Prehist. y Arqueol IV: 241-268.
- 1993: "Tradición y continuidad del arte rupestre en la Antigüedad Tardía. La Cueva de la Camareta". Antig. Crist. X: 433-448.

González Cabrera, F. J., Hervada Pascual, C. 2008: "Itinerarios por los yacimientos de arte rupestre del macizo de Santa María la Real de Nieva: Conócelos y respétalos". Caja Segovia. Obra Social y Cultural.

GonZALO QuintANILLA, F. 1970: "Arte Rupestre en la provincia de Segovia". Revista del Ejército 370: 5-9.

LUCAS Pellicer, M. ${ }^{a}$ R. 1973: "Grabados rupestres en Domingo García". XIII Congreso Nacional de Arqueología (Zaragoza): 257-26.

- 1974: El arte rupestre en la provincia de Segovia. Cuadernos de Prehistoria y Arqueología de la Universidad Autónoma: 57-69.

LUCAS DE VIÑAS, M. ${ }^{\text {R. }}$. 1971: "Grabados rupestres en la Comarca de Santa Maria de Nieva". Estudios Segovianos XXIII: 132-140.

MADOZ, P. 1849: Diccionario geográfico estadístico-histórico de España y sus posesiones de Ultramar VII. Madrid.

Martín Duque, J. F., Diez Herrero, A. 2005: "Las raices del paisaje: condicionantes geológicos del territorio de Segovia". Junta de Castilla y León. Valladolid.

Martin EscoRZA, C. 2006: Excursión a Domingo García y Santa María la Real de Nieva (Segovia). Arte en las piedras. Sociedad de Amigos del Museo Nacional de Ciencias Naturales.

Martín Santamaría, E., Mouré Romanillo, J. A. 1981: "El caballo de estilo paleolítico de Domingo García". Trabajos de Prehistoria 38: 97-108.

Ripoll López, S., Municio GonzÁlez, L. 1992: "Las representaciones de estilo paleolítico de Domingo García (Segovia)". Espacio, Tiempo y Forma, Serie I. Prehist. y Arqueol. V: 107-138.

- 1999: Domingo García. Arte rupestre Paleolítico al aire libre en la meseta castellana. Memorias. Arqueología en Castilla y León. Junta de Castilla y León.

Ripoll Pereló, E. 1990: "Acerca de algunos problemas del arte rupestre postpaleolitico en la Península ibérica". Espacio. Tiempo y Forma, S. I. Prehist. y Arqueol. 3: 71-104. 
- 2001: "El debate sobre la cronología del arte levantino". Quad. Preh. Arq. Cast. 22: 267-280.

SÁnchez Moreno, E. 2000: "Releyendo la campaña de Aníbal en el Duero (220 a. C.): La apertura de la meseta occidental a los intereses de las potencias mediterráneas". Gerión 18: 109-134.
SASTRE Blanco, J. C. 2006: "Una aproximación a la puesta en valor del arte esquemático y su paisaje. La Sierra de la Culebra (Zamora)". Arqueología y Territorio 3: 1-16.

TuÑón MaLlADA, P. 1929: "Estilizaciones rupestres ibéricas". Actas y Memorias de la Sociedad española de Arqueología, Etnología y Prehistoria VIII: 9-11. 